\title{
A guerra como tema no cinema brasileiro
}

William Reis Meirelles ${ }^{l}$

\section{RESUMO}

0 cinema desde o seu nascimento demonstra ser um potencial suporte de registro de memória, seja na forma documental, ou pelo imaginário que contém na forma de ficção, constituindo-se, assim, em uma fonte importante para conhecer e compreender o passado; neste texto são apresentados filmes que abordam a guerra nos seus enredos e sua relação com a História do Brasil.

Palavras-chave: guerra, cinema brasileiro, cinema e história, ensino de história

Desde os primeiros tempos o cinema tornou-se um auxiliar expressivo no contexto das guerras.

Durante a Primeira Grande Guerra conheceu-se um grande crescimento, impulsionado pelos serviços cinematográficos dos exércitos e de empresas privadas, preocupados em registrar os armamentos nas trincheiras do inimigo ou, a partir de pequenos aviões, filmando a formação de tropas no campo de batalha reunindo informações vitais para a elaboração das estratégias de ataque ou de defesa.

Os registros presentes nesses filmes são documentos históricos importantes e corresponde nas suas formas ao cinema como foi imaginado pelos Irmãos Lumiére, o documentário, onde a preocupação é captar através da câmara cinematográfica os acontecimentos de um modo muito próximo do real.

Outra forma do uso desse gênero de filme foi a larga utilização como instrumento de propaganda. Um exemplo é como foi utilizado pelos Estados Unidos no Brasil, dentro da chamada política de boa vizinhança, fornecendo

1 Professor Associado da Universidade Estadual de Londrina-UEL. Doutor em História e Sociedade pela UNESP (wreism@uel.br) 
filmes para serem montados nos jornais da "tela" locais que eram sendo projetados nos cinemas no Brasil.

Nesses jornais pode-se constatar o grande contraste entre as duas culturas: enquanto as imagens nacionais mostravam paisagens, festas, folclore, artesanato e matérias primas; os americanos exibiam sua indústria bélica, cinematográfica, siderúrgica, ou ainda, suas belezas naturais, seu sistema de ensino e a sua cultura.

Este breve relato teve por objetivo mostrar que o cinema desde o seu nascimento demonstra ser um potencial suporte de registro de memória, seja na sua forma documental, ou pelo imaginário que contém na forma de ficção, constituindo-se, assim, em uma fonte importante para o historiador que pretende conhecer e compreender o passado.

Neste texto serão apresentados filmes que têm como objeto nos seus enredos as guerras e história do Brasil. Este estudo tem como objetivo antes de tudo verificar como o homem se vê e representa a si mesmo e de que forma recria em imagens de um determinado período ou acontecimento histórico, especialmente num contexto de conflito armado entre nações.

Para entender a importância da relação do cinema com História é importante ressaltar que esta alcançou o status de ciência e disciplina acadêmica no final do século XIX, ao mesmo tempo em que surgiam na ỉndústria capitalista as inovações técnicas, como a fotografia, a gravura impressa, o cinema e o disco.

Como afirma Marc Ferro,

Assim aprendido, o filme histórico pouco difere das outras formas de discurso sobre a história: o romance histórico, trabalhos acadêmicos, etc. Mesmo com relação ao teatro, a especificidade do cinemaé mínima; claro, ela ocorre (ângulos de tomadas, planos gerais, primeiros planos, esbatimento de imagens, utilização mais elaborada da relação entre o som e a imagem, etc.) Com certeza, esses filmes contribuem para a inteligibilidade dos fenômenos históricos e para a difusão dos conhecimentos sobre a história, possuindo uma virtude pedagógica. Mas poucos intervêm como contribuição científica do cinema para a inteligibilidade dos fenômenos históricos (FERRO, 1976, p. 64).

${ }^{2}$ Havia uma norma, baixada pelo governo do Estado Novo, tornando obrigatória a exibição em todos os cinemas de um jornal cinematográfico brasileiro antes da exibição dos filmes de longa metragem. 
0 cinema como produto cultural não é inocente, como um veículo de difusão de idéias ele exerce grande influencia sobre as multidões. Escrever sobre filmes que abordam a história da guerra é mostrar seu papel enquanto arma poderosa para convencer as massas, tal como o fizeram americanos e, em especial, nazistas e fascistas europeus durante a Segunda Guerra Mundial.

Comparando-se à filmografia estrangeira, a brasileira é quase que inexistente. A média de produções apenas nos Estados Unidos nas décadas de 1940 e 1950 era de 450 filmes e no período de conflito parte expressiva dessa produção era de filmes voltados à propaganda e à guerra. A produção nacional pode ser dividida em três grupos de filmes: os que abordam a Guerra do Paraguai, as Guerras Mundiais - a Primeira e a Segunda ${ }^{3}$.

Dessa filmografia apenas os filmes mais recentes têm suas cópias preservadas; os mais antigos desapareceram corroídos pelo tempo e pela falta de conservação. Do período do cinema mudo (1896-1929) restam apenas uns poucos fragmentos e a maioria só é conhecida através de referências escritas e poucas fotografias que documentaram a produção guardada em arquivos e em publicações da imprensa.

Segundo alguns pesquisadores, do cinema mudo brasileiro conservouse menos de cinco por cento do que foi realizado. Já nas primeiras décadas do filme sonoro (a partir de 1930) houve um pequeno avanço graças à preocupação preservacionista de alguns realizadores, no entanto, somente a partir de 1949 com a criação da Filmoteca do Museu de Arte Moderna de São Paulo a preservação da memória cinematográfica começou a tornar-se realidade.

\footnotetext{
3 Todas as referências, fichas e sinopses foram extraídas dos seguintes textos: GUIA DE FILMES. Rio de Janeiro: Embrafilme, 1985- v. 1-1911/20 e 1987-v.2-1921/25. GUIZZ0, José Octávio. Alma do Brasil: Primeiro filme nacional de reconstituição histórica inteiramente sonorizado. Campo Grande(MS), 1984. RAMOS, Fernão (org.). Historia do Cinema Brasileiro. São Paulo: Art Editora, 1987. MIRANDA, Luiz Felipe. Dicionário de Cineastas Brasileiros / Luiz Felipe Miranda. São Paulo: Secretaria de Estado da Cultura: Art Editora, 1990. VIANY, Alex. Introdução ao Cinema Brasileiro. Rio de Janeiro: MEC/INL, 1959.
} 


\section{Guerra do Paraguai}

No primeiro grupo de filmes estão aqueles que abordam a Guerra do Paraguai. Em 1917 foi lançado em São Paulo o filme Os Heróis Brasileiros na Guerra do Paraguai $i^{4}$, provavelmente o primeiro filme nacional a tratar da temática histórica da guerra; seu conteúdo abordava o episódio da Retirada da Laguna e foi anunciado na imprensa como um "empolgante drama histórico de 1865", "a resistência de 18 brasileiros à vanguarda dos paraguaios invasores", um filme histórico "e patriótico onde o Tenente Antonio João, comandante do forte de Coimbra, com meia dúzia de soldados, resistiu heroicamente à invasão estrangeira".

Abordando o mesmo acontecimento Libero Luxardo e Alexandre Wulfes realizaram em 1932, na cidade de Campo Grande (MS), o filme Alma do Brasil, o primeiro de reconstituição histórica sonorizado. Seus autores procuraram ser fieis aos acontecimentos como foram descritos no livro do visconde de Taunay (Alfredo D'Escragnolle, mais tarde conhecido como Visconde de Taunay) e, ainda, de fotografias da Guerra do Paraguai. 0 elenco de quase trezentas pessoas teve além dos atores civis, a participação dos soldados da Brigada Mixta, do general Bertoldo Klinger, que na época da filmagem, realizava manobras na regiãos.

Por ocasião do seu lançamento no Rio de Janeiro, em plena Revolução de 32, teve problemas com a censura, pois nas cenas iniciais aparecia ao lado do então coronel Dutra o general Klinger, aliado dos paulistas revoltosos e que estava na cadeia. 0 filme, para não ter a exibição proibida teve aquelas cenas substituídas por quadros com uma tarja no meio.

Em 1960, foi lançado um filme de Walter Hugo Khouri, Na Garganta do Diabo ${ }^{6}$, um enredo de ficção na Guerra do Paraguai, não aborda diretamente

\footnotetext{
${ }^{4}$ HERÓIS BRASILEIROS NA GUERRA DO PARAGUAI, OS (também aparece com os seguintes títulos: Morte Gloriosa do Tenente Antônio João, A; Retirada da Laguna, A). Longa metragem em $35 \mathrm{~mm}$. a 16 qps. Produzido pela Ipiranga Filmes (SP) e lançado em 15 de outubro de 1917, na sala de exibição Congresso, em São Paulo. 0 filme teve como produtores a Familia Lambertini; e as cenas foram dirigidas por Achilles e Giorgio Lambertini; de um roteiro baseado no libreto de Eugênio Egas. 0 operador de câmara foi Antonio Campos e o elenco: Dudu, Vitória Lambertíni, Luisa Lambertini, Argentina Lambertini, Achilles Lambertini, Dora Lambertini, Emnia Lambertini.

5 O ESTADO DE S. PAULO, 12 de fevereiro de 1985, p. 16 -

${ }^{6}$ NA GARGANTA DO DIABO (Brasil, 1959). 100 min, P\&B. Direção e roteiro: Walter Hugo Khouri. Elenco: Luigi Picchi, Odete Lara, Fernando Baleroni, Sérgio Hingst, José Mauro de Vasconcelos, Milton Ribeiro, Edla Van Steen, André Dobroy.Lançado em São Paulo em 1960.
} 
a guerra, reúne como personagens uma família e dois soldados brasileiros, desertores, que em fuga ocupam a casa da fazenda, localizada na fronteira entre Brasil e Argentina; as águas do Rio Iguaçu fazem o pano de fundo. 0 pai para defender um pequeno tesouro que acumulara, para não entregá-lo, preferiu ver seus filhos serem torturados e mortos pelos invasores. 0 enredo reúne apenas oito personagens e centra-se mais nos seus conflitos pessoais, quase um contraponto à violência da guerra propriamente dita. No filme pode-se apreciar as imagens das Sete Quedas do rio Iguaçu, atualmente encoberta pelas águas do lago de Itaipu.

Na década de 80, Silvio Back, um cineasta que tem se destacado por filmes que buscam recuperar nosso passado, realizou Guerra do Brasil $(1978)^{7}$, um documentário que mostra várias interpretações sobre a Guerra do Paraguai. A discussão corre por conta de especialistas que, na medida em que Guerra do Brasil desfila os episódios, confrontam suas opiniões.

\section{Primeira Grande Guerra}

Sobre o período da Primeira Guerra são poucas referências, apenas filmes mudos. Manifestação dos Aliados $(1919)^{8}$ relacionado às comemorações pela colônia italiana de São Paulo pelo fim da guerra e com a mesma finalidade A Vitória da Itália $(1919)^{9}$, mostra festa promovida pelo Círculo Italiano. Conforme noticiado na época "cerca de 50.000 pessoas apanhadas pela objetiva, isto é, o recordista em filmes nacionais em número de pessoas".

0 filme Castigo do Kaiser, O (Vitória dos Aliados, A) ${ }^{10}$, é um documentário que apresenta as "manifestações de regozijo nas ruas, pelo fim da guerra". É um documentário sobre o segundo carnaval de 1918, feito em

7 GUERRA DO BRASIL (Brasil, 1987) pesquisa, roteiro, texto, produção e direção. Co-produção: Embrafilme (RJ).

8 MANIFESTAÇÃO DOS ALIADOS. 35mm, 16q., São PauloSP, Carrari Filme; lançado em 25.1. 1919, no Cine Pathé (SP). Produtor-diretor Arturo Carrari, operador José Carrari.

9 VITÓRIA DA ITÁLLA, A. 35mm, 16q., São Paulo. Produtora: Italo-Americana Carrari Filme, Iançado em 5.1.1919, no Cine Central (SP). Produtor-diretor Arturo Carrari, operador José Carrari. Uma fonte relaciona este filme com outro: Duas Grandes Demonstrações da Colônia Italiana em São Paulo pela Vitória.

${ }^{10}$ CASTIGO DO KAISER, O (também com o título: Vitória dos Aliados, A). 35mm, 16q., Rio de Janeiro-DF, em novembro de 1918. Produtor: Nacional Filmes; operador: Alberto Botelho. Exibido em São Paulo nos Cinemas Central e Royal, em 12.3.1919. 
novembro para comemorar a vitória dos Aliados. Em um jornal era anunciado como "um filme consagrado à grande vitória do direito sobre a força, um trabalho detalhado de todas as homenagens prestadas no Rio de Janeiro aos Aliados que fará vibrar de entusiasmo a alma brasileira."

Pátria e Bandeira ${ }^{11}$, do português Simões Coelho, realizado em 1918, no Rio de Janeiro, não é propriamente um filme de guerra, mas seu argumento focalizando a espionagem alemã em nosso território está relacionado à Primeira Guerra. 0 filme foi classificado por um jornal da época como "uma ingênua veleidade patriótica" 0 diretor contou com a colaboração e participação das forças armadas e da aviação militar.

\section{Segunda Guerra Mundial}

Os filmes sobre a Segunda Guerra constituem-se no maior número de produções tanto documentários, como ficções.

Dois documentários podem ser destacados por terem 0 apoio do governo como produtor; um patrocinado pelo DIP (Departamento de Imprensa e Propaganda), Jornada Heróica (Brasil, 1945-47), realizado por Alexandre Wulfes que reuniu cenas dos jornais cinematográficos de arquivo da instituição. 0 outro foi produzido pelo Instituto Nacional de Cinema Educativo INCE, cabendo a Alberto Salvá a responsabilidade pela execução do documentário, Segunda Guerra Mundial (1965-67). 0 filme reúne imagens do cine jornal Fox Movietone e este com o primeiro reúne cenas da participação da FEB na Itália.

Duas comédias musicais de Luis de Barros - chanchadas - parodiam a guerra fazendo referências aos alemães: Samba em Berlim ${ }^{12}$ (1943) e Berlim na Batucada ${ }^{13}$ (1944). Essas comédias produzidas pela Cinédia tinham como pano de fundo a Segunda Guerra Mundial e parodiam a Política da Boa

${ }^{11}$ PATRIA E BANDEIRA (Brasil, 1918). Produção: Brasil Filmes, direção de José Simões Coelho, argumento: Cláudio de Souza, produtor e câmera: Antonio Leal. Elenco: Ema Póla, Leonardo Loponte, Júlio Munhoz, Castelo Branco, Emílio Aires.

${ }^{12}$ SAMBA EM BERLIM (Brasil, 1943). Produção: Cinédia, diretor: Luiz de Barros. Elenco: Mesquitinha, Brandão Filho, Dercy Gonçalves, Grande Otelo, Silvino Neto, Ziembinski.

${ }^{13}$ BERLIM NA BATUCADA (Brasil, 1944). Produção: Cinédia, diretor: Luiz de Barros. Elenco: Procópio Ferreira, Delorges Caminha, Chocolate, Francisco Alves, Jararaca e Ratinho. 
Vizinhança de Roosevelt. Berlim na Batucada mistura efeitos da guerra no Brasil e a chegada de um americano à procura do carnaval; o personagem é uma paródia de Orson Welles, o cineasta enviado como embaixador cultural pelos Estados Unidos ao Brasil em 1942.

Samba em Berlim é uma comédia musical carnavalesca e tem com enredo dupla de personagens que muda para o Rio de Janeiro e se alistam para a guerra. 0 filme teve uma cena cortada pela censura, era um número musical que no cenário, um telão ao fundo, mostrava Stalin dentro de um barco.

Em 1946, do mesmo diretor, uma nova comédia, Caídos do Céu $u^{14}$, mostra um casal do século 18 que cai no Rio de Janeiro durante o carnaval, quando se comemora o sucesso dos alia-dos contra o Eixo. Durante esse período a produção de filmes sofreu as restrições da guerra, pois todo material de filmagem era importado o que provocou uma crise que se prolongou até 1951.

0 dia 26 de fevereiro de 1944 marcou o lançamento nos cinemas do Rio de Janeiro o filme O Brasileiro João de Souza ${ }^{15}$ que conta a história de marinheiro do Loide João de Souza, cujo pai morrera em 1917, no primeiro navio brasileiro afundado pelos alemães. Foi preso e demitido ao provocar um conflito em um bar de Porto Alegre freqüentado por nazistas. Acabou sendo readmitido, pois os diretores do Loide levaram em conta que a briga tivera cunho patriótico e, assim, João de Souza retorna ao mar.

0 filme termina com uma mensagem vinda dos Estados Unidos comunicando que falecera João de Souza, único sobrevivente do navio mercante brasileiro Cacique, torpedeado pelos submarinos alemães e a imagem final mostra aviões da FAB, em formação de "V" retornado de uma ação de patrulhamento. 0 filme tem, sem dúvida, um conteúdo antinazista. Seu diretor, declarou em entrevista que escolheu o título do filme ao constatar que quatorze das vítimas dos navios torpedeados pelos alemães chamavam-se João de Souza.

${ }^{14}$ CAÍDOS DO CÉU (Brasil, 1946). Produção: Cinédia/Adhemar Gonzaga. Direção, roteiro, cenografia e montagem: Luiz de Barros. Elenco: Dercy Gonçalves, Walter D'Avila, Vinda Batista, Ataulfo Alves, Violeta Ferraz, Chocolate, Francisco Alves, Marlene, Trio de Ouro, Adoniran Barbosa, Isaurinha Garcia.

15 O BRASILEIRO JOÃO DE SOUZA (Brasil, 1943). Produção Cinex (RJ). Diretor: Bob Schust, câmera; John Reichenheim. Elenco: Sandro Poloni, Lu Marival, Ziembinski. 
A tomada do Monte Castelo e a atuação da Força Expedicionária Brasileira (FEB) serviram de tema para um drama de guerra realizado por Luis de Barros em 1961, Por um Céu de Liberdade ${ }^{16}$. 0 filme recebeu do comandante brasileiro, Mascarenhas de Moraes, carta de elogio, uma obra "que exalta a FEB e dignifica o Exército Brasileiro".

Aleluia Gretchen (1964) ${ }^{17}$, filme de Silvio Back, trata das relações e conflitos entre o nazismo e o integralismo brasileiro através de uma família de imigrantes alemães, os Kranz, que se instalam no Paraná na década de 30.

De todos os filmes que abordaram a participação do Brasil na Segunda Guerra, Rádio Auriverde (1990-1) ${ }^{18}$, de Silvio Back, foi o que provocou muita polêmica. Pracinhas veteranos da guerra cercaram os cinemas onde era exibido, entregavam panfletos à população, criticando o filme e em algumas cidades grupos se reuniram e tentaram impedir sua exibição.

0 filme é um documentário que reúne o som de programas de rádio - a chamada Rádio Auriverde - voltados exclusivamente para as tropas e imagens da época que mostravam soldados em poses descontraídas e, até, debochadas. As imagens foram montadas ironicamente opondo-se às palavras da trilha sonora. Ao utilizar o recurso de oposição entre imagem e som 0 autor procurava desmistificar uma construção idílica presente na transmissão radiofônica, enquanto as imagens mostravam uma realidade bem diferente.

${ }^{16}$ POR UM CÉU DE LIBERDADE (Brasil-1961) Empresa Paulista Cinematográfica e Condor Filmes, Sgo Paulo-Rio. Direção de Luiz de Barros. Produção de Paulo Sá Pinto. Argumenlo e roteiro de Daniel Rocha e Jairo Pinto de Araújo. Narração de Maurício Kus. Fotografia de Afrodísio de Castro. Montagem de José Canizares. Música de Rafael Puglielli. Elenco: John Herbert, Lia Cortese, Odilon Azevedo, Luiz Mazzei, Delorges Caminha, Otello Zelloni, Raul Matta, Yolanda Fronzi, Black-Out, J. Rosa, Paulo Padilha, M. Dourado, Hélio Montercv, Paulo Copacabana, Maria Gladys, Vicente Marchelli, Rafael de Carvalho, M. Guímarães, Edson Silva, Hélio Duda. Sinopse: drama de guerra sobre a atuação da Força Expedicionária Brasileira e a tomada de Monte Castelo, no fronte italiano, durante a Segunda Guerra Mundial. Lançado no Cinema Plaza no dia 27 de novembro de 1961.

${ }^{17}$ ALELUIA, GRETCHEN (Brasil, 1976). Diretor Silvio Back Roteiro Sylvio Back, Manoel Carlos Karam, Oscar Milton Volpini. Elenco Carlos Vereza, Miriam Pires, JoséMaria Santos, Lillian Lemmertz, Selma Egrei. Sinopse: História de uma família que foge da Alemanha nazista desembarcando no Brasil, por volta de 1937, onde compra um hotel, que se torna ponto de simpatizantes do nazismo, mas enfrentam muitos problemas de adaptação. Realizado em plena ditadura militar, o filme discute seriamente a atuação de adeptos do nazismo no país.

${ }^{18}$ RÁDIO AURIVERDE. (Brasil, 1990-1) Pesquisa, roteiro, texto, produção e direção Silvio Back. Co-produção: Embrafilme (RJ). 
Recentemente, ambientado em Natal (RN), o filme For All - O Trampolim da Vitória ${ }^{19}$ procurou mostrar o cotidiano e as relações entre brasileiros e americanos instalados em Parnamirim Field, a base aliada montada em nosso território durante a II Guerra Mundial.

A Cobra Fumou ${ }^{20}$ é um documentário sobre a participação do $1^{\circ}$ Grupo de Aviação de Caça na Segunda Guerra através de cenas da época e de depoimentos de seus veteranos pilotos. 0 filme é o segundo de um projeto da produtora BSB Cinema, que pretende registrar numa trilogia a participação brasileira na $2^{\mathrm{a}}$ Guerra Mundial. 0 primeiro, Senta a Pua ${ }^{21}$, foi exibido no Festival de Cinema de Brasilia do ano passado. 0 terceiro, Operação Atlântico, é sobre a marinha mercante e de guerra durante a primeira metade dos anos 40.

0 filme de produção mais recente onde a guerra aparece como tema é Olga ${ }^{22}$. Narra a história da judia alemã 0lga Benário Prestes (1908-1942), militante comunista desde jovem com Luís Carlos Prestes líder do PCB.

${ }^{19}$ FOR ALL-TRAMPOLIM PARA A VTTÓRIA. (Brasil, 1997). Diretor Luiz Carlos Lacerda e Buza Ferraz. Roteiro Joaquim Assis, Luiz Carlos Lacerda e Buza Ferraz. Elenco Betty Faria,, José Wilker, Paulo Gorgulho, Caio Junqueira, Erik Svane, Alexandre Lippiani, Luiz Carlos Tourinho, Flávia Bonato, Daniela Duarte, Alexandre Barros, Cláudio Mamberti, Edson Celulari, Carlos Ferreira, Raul Gazolla, Paulo César Grande, Ney Latorraca, Felipe Martins, Nelson Pereira dos Santos (Almirante Jones), Guaracy Picado (Franklin Roosevelt), Ernesto Piccolo, Paulo Reis, Diogo Vilela. Sinopse: A convivência de brasileiros com soldados americanos na base de Parnamirim Field, em Natal (RN), durante a II Guerra Mundial. A história se desenrola em torno de uma familia de classe média, os Sandrini, que são abalados pelas novas circunstâncias: amores inesperados, reflexos de intrigas políticas, desafios aos preconceitos e testes para a coragem.

${ }^{20}$ A COBRA FUMOU (Brasil, 2002) Diretor: Vinícius Reis. Documentário que nos permite ver um pouco dos estilos de vida de ex-pracinhas já na casa dos 80-90 anos.

${ }^{21}$ SENTA PUA. (Brasil, 1999). Diretor Erick de Castro. Documentário. Depoimentos: Brigadeiro Corrêa Netto, Brigadeiro Rui Moreira Lima, Brigadeiro Meira, Brigadeiro Neiva, Brigadeiro Joel Miranda, entre outros.

22 OLGA (Brasil, 2004) Direção: Jayme Monjardim. Baseado no livro de Fernando Morais. Elenco: Camila Morgado, Caco Ciocler, Fernanda Montenegro, Mariana Lima, Renata Jesion, Osmar Prado, Luis Mello, Eliane Giardini, Jandira Martini, Werner Schünemann, Guilherme Weber, Floriano Peixoto, Murilo Rosa, José Dumont, Milena Toscano, Oscar Simch, Odilon Wagner, Eliana Guttman, Paschoal da Conceição, Sabrina Greve, Ranieri Gonzáles, Leona Cavalli, Edgar Amorim, Maria Clara Fernandes, Bruno Dayrrel, Raul Serrador. Sinopse: Olga Benário é uma militante comunista desde jovem, que é perseguida pela polícia e foge para Moscou, onde faz treinamento militar. Lá ela é encarregada de acompanhar Luís Carlos Prestes ao Brasil para liderar a Intentona Comunista de 1935, se apaixonando por ele na viagem. Com 0 fracasso da revolução, Olga é presa com Prestes. Grávida de 7 meses, é deportada pelo governo Vargas para a Alemanha nazista e tem sua filha Anita Leocádia na prisão. Afastada da filha, Olga é então enviada para o campo de concentração de Ravensbrück. 
A pequena produção de filmes sobre as guerras procurou exaltar ou reiterar as histórias construídas sobre os eventos que eram os seus objetos, a exceção foi Silvio Back que procurou, de modo irônico, fazer uma crítica no documentário Radio Auriverde de uma construção institucionalizada da história sobre a participação do Brasil na Segunda Guerra omitindo as dificuldades por que passaram nossos pracinhas na Itália.

\section{Referências}

FERRO, M. Cinéma et Histoire. Paris, Denoel / Ghonthier, 1976

EMBRAFILME. GUIA DE FILMES. Rio de Janeiro: Embrafilme, 1985- v. 1-1911/20 e 1987- v.2-1921/25.

GUIZZ0, J. 0. Alma do Brasil: Primeiro filme nacional de reconstituição histórica inteiramente sonorizado. Campo Grande(MS), 1984.

RAMOS, F. (org.). Historia do Cinema Brasileiro. São Paulo: Art Editora, 1987.

MIRANDA, L. F. Dicionário de Cineastas Brasileiros / Luiz Felipe Miranda. São Paulo: Secretaria de Estado da Cultura: Art Editora, 1990.

VIANY, A. Introdução ao Cinema Brasileiro. Rio de Janeiro: MEC/INL, 1959.

O ESTADO DE S. PAULO, São Paulo, 12 de fevereiro de 1985.

\section{The war as a theme in the Brazilian movies}

ABSTRACT

Since its birth, cinema demonstrates to be a potential support of memory registration, either in the documental form or for the imaginary contained in the fiction form, thus being an important source to know and understand the past. In this paper films approaching the war in its plots and its relationship with the History of Brazil are presented.

Key words: war, Brazilian movies, movies and history, history teaching 